\title{
Post-traumatic stress disorder: a review of DSM criteria and functional neuroanatomy
}

\author{
Cornelius W. Thomas, MD
}

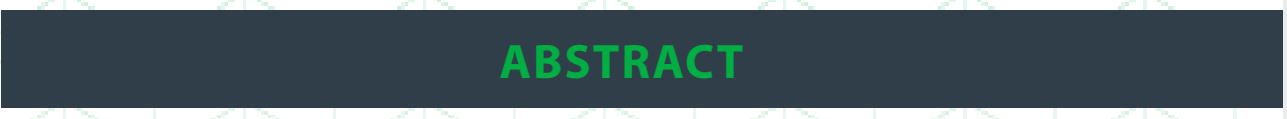

The Diagnostic and Statistical Manual of Mental Disorders (DSM-5) criteria for posttraumatic stress disorder (PTSD) consists of over twenty possible symptoms that can be divided into six broad categories. These categories correlate with specific brain networks that regulate emotions, behaviors, and autonomic function. Normal functioning of these networks depends on two key regions: the prefrontal cortex and the amygdala. The prefrontal cortex provides top-down executive control over amygdala, whereas the amygdala is critical for threat detection and activation of the 'fight or flight' response. Events that trigger extreme and/or prolonged fear can cause persisting dysregulation within the prefrontal-amygdala circuit, resulting in PTSD symptomatology. Studies indicate that effective treatment of PTSD, either psychotherapy or medication, reverses this prefrontal-amygdala dysregulation. This review article summarizes current knowledge and theories available in the medical literature from NCBI's PubMed database regarding the underlying brain networks involved in PTSD.

\section{KEYWORDS}

post-traumatic stress disorder, PTSD, neuroanatomy, amygdala, prefrontal cortex, network

\section{INTRODUCTION}

In 1952, the American Psychiatric Association published the first edition of the Diagnostic and Statistical Manual of Mental Disorders (DSM), which included the diagnosis of gross stress reaction (GSR), a condition caused by an identifiable traumatic experience. ${ }^{1}$ Events such as "combat" or "civilian catastrophe (fire, earthquake, explosion, etc.)" could cause "great and unusual stress". Symptoms resulted from the patient's attempt "to deal with overwhelming fear" and caused a "transient situational personality disturbance". In DSM-III, gross stress reaction was change to posttraumatic stress disorder (PTSD). ${ }^{2}$ According to diagnostic criteria, traumatic events could include the following: a serious threat to the individual's life or physical integrity, serious threats to the life and safety of others, or the sudden destruction of one's home or community.
Published in 2014, DSM-5 criteria include more than twenty potential symptoms, which can be divided into 6 broad categories (Table 1). These categories correlate with specific functional brain networks. ${ }^{3}$

\section{BASIC NEUROBIOLOGY}

PTSD symptoms develop due to dysfunction in two key brain regions, the amygdala and the prefrontal cortex. The amygdala, a small almond shape structure located in the medial temporal lobe, contains several clusters of neurons. Functional activities attributed to these neurons include environmental threat detection, activation of defensive behaviors ('fight or flight' response), activation of the sympathetic nervous system (SNS), and facilitation of new memory formation. ${ }^{4}$ Neurons within the prefrontal cortex (PFC) regulate conscious awareness and volitional control over emotions, attention, memory and behaviors. ${ }^{5,6}$ Functional activity within the PFC can 
Table 1. Summary of DSM 5 Criteria:

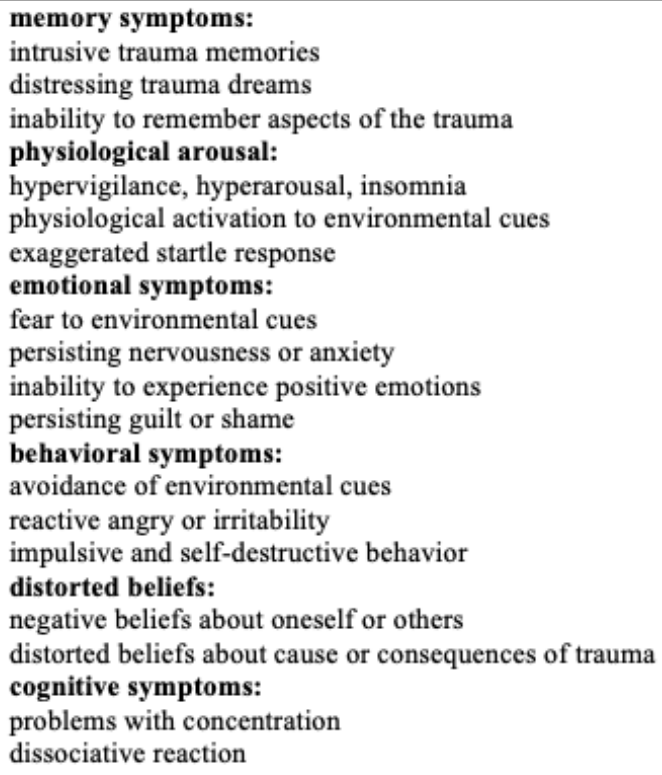

cingulate cortex. ${ }^{17}$ Two major projection fibers, the fornix and the cingulum, connect these regions to form a functional circuit (Figure 1). James Papez first demonstrated this circuit in 1937 by injecting rabies virus into the hippocampus of a cat and traced the movement of the virus through the brain (Papez circuit). ${ }^{18}$

The hippocampus receives information about the environment from sensory cortices via the following pathways: the dorsal and ventral visual streams, the auditory processing stream, and the olfactory tract. ${ }^{19,20}$ During periods of wakefulness, the hippocampus

be localized to specific regions as follows: medial PFC regulates emotions and memory, orbital (ventral) PFC regulates behaviors, and lateral PFC regulates attention. ${ }^{8}$

During the initial response to an environmental threat, neurons within the amygdala trigger defensive behaviors and physiological arousal (fear response). Simultaneously, neurons within the medial PFC engage in the conscious assessment of the threat and either suppresses or enhances the fear response. ${ }^{9,10,11}$ Functional imaging studies (PET scans and fMRI) in individuals with PTSD show hyperresponsiveness of the amygdala and decreased activity of the medial PFC to potential threats. ${ }^{12,13}$ These findings are consistent with the theory that PTSD symptoms result from hyper-reactivity of the amygdala's fear response and failure of the medial PFC to provide inhibitory feedback. ${ }^{14,15,16}$

\section{TRAUMATIC MEMORIES}

Regions critical for the formation and retrieval of autobiographical memory include hippocampus, thalamus and facilitates storage of sensory information into short-term memory. ${ }^{21}$ The amygdala also receives information from sensory cortices and facilitates long-term memory formation by triggering a state of hyper-arousal, and events that are not emotionally significant will typically be forgotten within four to six weeks. ${ }^{22,23,24}$ Preliminary research suggest that medications that block peritraumatic hyper-arousal, such are propranolol, may decrease the risk of PTSD following traumatic events. ${ }^{25}$ 
Long-term memory consolidation results from new dendritic spine growth and formation of new dendritic connections within regions of the memory network, especially the hippocampus and the anterior cingulate cortex. ${ }^{26,27}$ The anterior cingulate cortex projects to the medial PFC, a region that assigns personal meaning and emotional significance to experiences, and controls intentional retrieval of autobiographical memory (top-down processing). ${ }^{28,29,30}$ Another key component of the memory networks is the posterior cingulate cortex, which provides vivid details about past events (i.e. visual images) through direct connections to the medial parietal sensory cortex..$^{30}$

For individuals with PTSD, trauma-related cues trigger intrusive memories through unintentional recall. Functional imaging studies have shown that cues activate the amygdala (bottom-up processing), which in turns activates other components of the memory circuit. ${ }^{31,32}$ Vivid sensory flashbacks, consisting of visual images, can be triggered by the activation of sensory cortices (i.e. visual cortex). ${ }^{33}$

Prolonged exposure therapy, which involves reviewing and discussing past trauma, has been shown to reduce intrusive memories. ${ }^{34}$ Functional imaging studies indicate that exposure therapy engages medial PFC in self-referential thinking, thereby promoting more rational appraisal of the causes and consequences of traumatic events..$^{35,36}$

Dreams, which occur primarily during REM sleep, activate regions within the memory circuit, including the hippocampus, amygdala, cingulate cortex and secondary sensory cortices. ${ }^{37}$ PTSDrelated nightmares may activate the sympathetic nervous system resulting in distressful night-time awaking, or may trigger physical activity based on the 'fight or flight' response (punching, kicking). ${ }^{38,39}$ Studies indicate that the frequency and intensity of trauma-related dreams decrease with psychotherapy involving dream review and imagery revision, a process that engages the PFC in conscious restructuring of dreams. ${ }^{40,41}$

\section{PHYSIOLOGICAL REGULATION}

Individuals with PTSD experience physiological arousal when thinking about past traumatic events or following exposure to trauma-related cues. Neurons within the lateral hypothalamus modulate physiological arousal by activating the sympathetic nervous system and hypothalamic-pituitaryadrenal (HPA) axis (neuroendocrine response). ${ }^{42}$ Studies have consisting shown physiological hyperresponsiveness, as measured by skin conductance or cardiac physiological, in individuals with PTSD. ${ }^{43,44}$

The amygdala projects to neurons within the lateral hypothalamus through the ventral amygdofugal pathway and stria terminalis, and the medial prefrontal cortex connects to the same neurons by projecting to the bed nucleus of the stria terminalis. The amygdala activates neurons in the lateral hypothalamus, whereas the medial prefrontal cortex either activates or suppresses these same neurons (Figure 2). ${ }^{45,46,47}$ Direct bidirectional projection neurons within the amygdofugal pathway and uncinate fasciculus connect the amygdala and medial PFC, and facilitate activity between these two regions. Collectively, the medial prefrontal cortex, the amygdala and the lateral hypothalamus form a physiological regulating network. ${ }^{42,48,49}$

Another structure that is critical to physiological arousal is the locus coeruleus (figure 3$).^{50}$ This small nucleus located in the brainstem contains most of

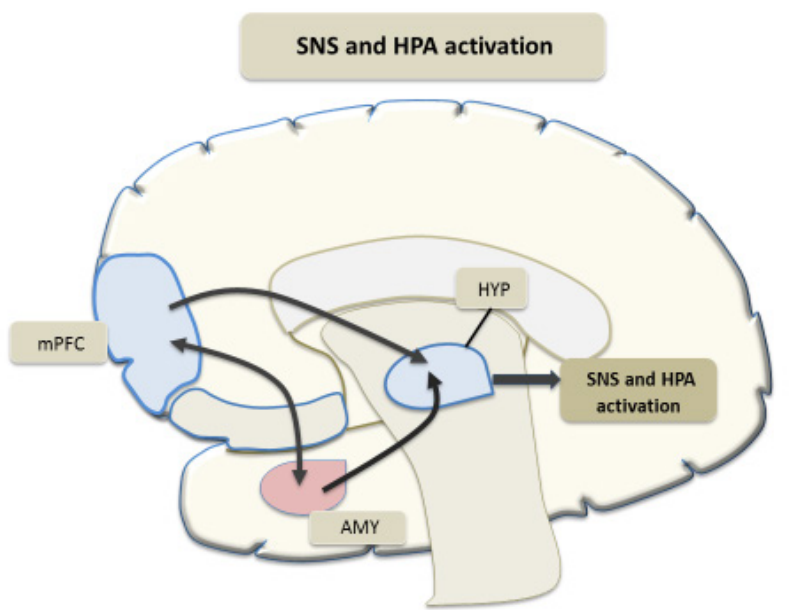

Figure 2: Sympathetic nervous system (SNS) and HPA axis regulation: amygdala (AMY), hypothalamus (HYP), medial prefrontal cortex (mPFC). 


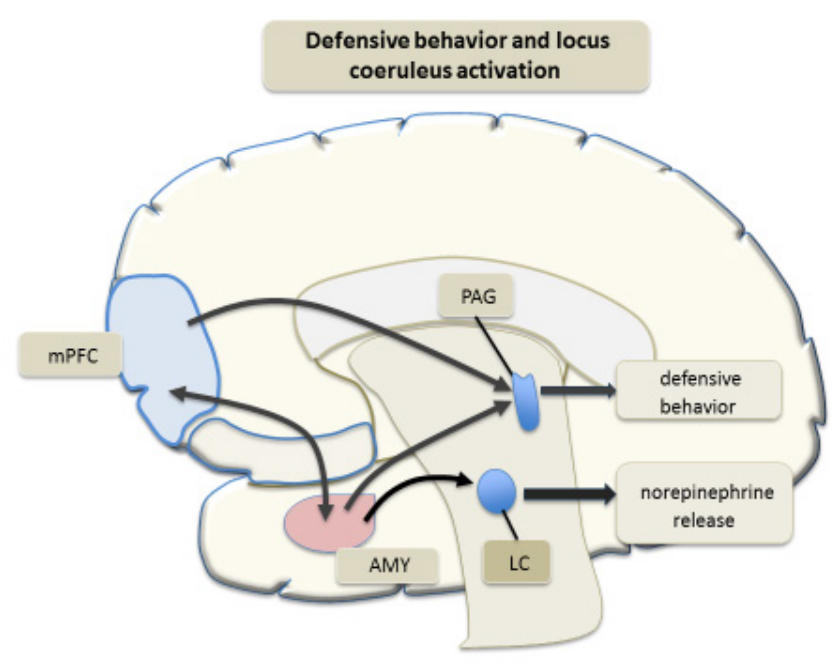

Figure 3: Defensive behavior and LC activation: amygdala (AMY), locus coeruleus (LC), medial prefrontal cortex (mPFC), periaqueductal gray (PAG). (brainstem nuclei) can generate rapid defensive motor responses (figure 3). In animal studies, stimulation of neurons within periaqueductal gray matter can trigger jumping, running, freezing, and increased overall muscle tone. ${ }^{60}$ In one recent functional MRI study, increased activity of periaqueductal gray matter was demonstrated in individual with PTSD. ${ }^{61}$ Stimulation of the nucleus reticularis pontis caudalis triggers the acoustic startle reflex with rapid onset of body defensive posture; a reaction that has been shown to be hyper-responsive with PTSD. ${ }^{62,63}$ The amygdala sends direct projections to the periaqueductal gray matter and the nucleus reticularis pontis caudalis, and potentiates these defensive

the brain's norepinephrine producing neurons, with efferents that project throughout the neocortex. Increased release of norepinephrine from the locus coeruleus causes hyper-arousal, hypervigilance and sleep inhibition. ${ }^{51}$ Studies indicate that activation of amygdala projections to the locus coeruleus increase release of norepinephrine; whereas medial PFC projections either enhance or suppress norepinephrine release. ${ }^{51,52,53}$ Studies in individuals with PTSD have shown increased activity of the locus coeruleus, which can trigger a state of anxious arousal. ${ }^{54,55} \mathrm{In}$ an attempt to reduce this anxious arousal, patients commonly engage in low stimulation seeking behaviors (social avoidance and isolation).

Central acting adrenergic agents, such as prazosin and clonidine, block the effects of norepinephrine in the neocortex. These agents can decrease hypervigilance and improve sleep in PTSD. ${ }^{56}$ Additionally, the practice of biofeedback or mindfulness-based meditation may reduce autonomic arousal and improve PTSD symptoms by down-regulating amygdala activity and improve prefrontal-amygdala functional intergration. . $^{57,58,59}$

\section{DEFENSIVE MOTOR RESPONSE}

Activation of neurons within the periaqueductal gray matter and the nucleus reticularis pontis caudalis responses. ${ }^{64,65,66}$

\section{BEHAVIORAL SYMPTOMS}

Behavioral changes, such as impulsivity and reactive anger, are common following severe emotional trauma and reflect dysfunction of brain regions that modulates behavior. Studies have shown that the nucleus accumbens (NA), a small group of neurons within the basal forebrain, plays a critical role in behavioral control and impulsivity. ${ }^{67}$ The nucleus accumbens acts an interface between the amygdala, the orbital PFC and the motor cortex (Figure 4). Collectively these regions form a network that regulates social behavior. This network can be summarized as follows: the orbital PFC sends bidirectional projecting fibers to the amygdala through uncinate fasciculus, both the orbital PFC and the amygdala send direct projection fibers to the nucleus accumbens (NA), and the nucleus accumbens connects to the supplementary motor cortex through the thalamus..$^{68,69,70}$

The amygdala promotes impulsivity by enhancing "motor readiness" to respond to external situations, whereas the orbital PFC normally suppresses impulsivity by modulating amygdala and nucleus accumbens activity. ${ }^{71,72,73}$ In human studies, damage to the orbital PFC triggers significant change in social behavior, with an increase in risk-taking, 


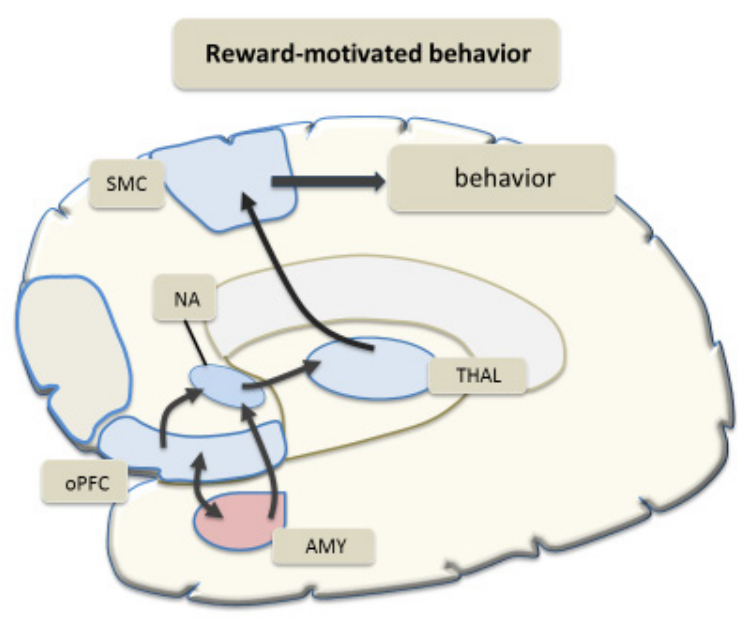

Figure 4: Regulation of reward-motivated behavior: amygdala (AMY), nucleus accumbens (NA), orbital prefrontal cortex (OPFC), supplementary motor cortices (SMC), thalamus (THAL).

aggressiveness, and impulsivity. ${ }^{74,75}$ Recent studies have demonstrated changes in functional activity and volume of the orbital PFC in patients with PTSD, which may explain the reactive aggression that occurs with this disorder. ${ }^{76,77,78,79}$

\section{EMOTIONAL SYMPTOMS}

The insular cortex, a region involved with introspective emotional awareness, receives ascending peripheral viscerosensory projections via the thalamus, and direct projections from the amygdala (Figure 5). ${ }^{80,81,82,83}$ Functional imaging studies suggest that activation of the amygdala-insula circuit generates feelings of fear and anger, and over-activity of this circuit may cause generalized fear, anger and decreased positive emotions in PTSD. . $^{84,85,86}$

The insular cortex has strong bidirectional connections with the medial prefrontal cortex, a region that controls self-referential thinking and effortful regulation of emotions. ${ }^{80,81,83,87,88,89,90}$ Studies have indicated that activation of the amygdala-insula circuit suppresses medial PFC activity and impacts emotional regulation. ${ }^{85,86}$ Therefore, impairment of emotional regulation seen with PTSD may result from overactivity of the amygdala-insula circuit. ${ }^{86}$ Exposure psychotherapy and selective serotonin reuptake inhibitors (SSRIs) have been shown to increase PFC activity with improved emotional regulation in individuals with PTSD. ${ }^{91,92,93,94}$

The experience of anxiety and nervousness can be trigged by activation of the sympathetic nervous system (SNS). ${ }^{95}$ Viscerosensory feedback of SNS activity occurs through fibers that project to the insular cortex via the thalamus. In PTSD, anxiety and nervousness occur in the context of SNS arousal to traumarelated cues. As a potential treatment option, one recent study showed a decrease in SNS activation to traumatic memories, as measured by skin conductance and heart rate response, in patients treated with propranolol. ${ }^{96}$ However, no data on symptom response was provided in this study.

\section{CONCLUSION}

Post-traumatic stress disorder can be conceptualized as a syndrome that results from prefrontal-amygdala dysregulation. ${ }^{13,14,15,97,98}$ Although the nomenclature is often inconsistent and can be confusing, knowledge of basic neuroanatomy is important in understanding symptom patterns and for the treatment of PTSD.

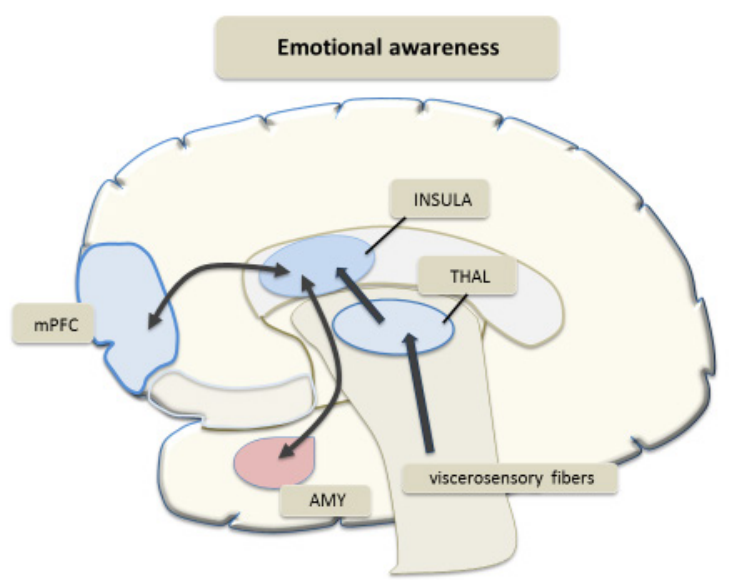

Figure 5: Emotional awareness: amygdala (AMY), insula cortex, medial prefrontal cortex (MPFC), thalamus (THAL). 
PTSD symptoms can be grouped into categories based on distinct functional networks. A key structure in these networks is the amygdala. The amygdala has been called the 'reptilian' or 'primal' brain because of its critical role in activation of the fight or flight response. ${ }^{99,100}$ The amygdala becomes over-active and hyper-responsive following severe life-threatening trauma or trauma that threatens the integrity of the self (e.g., sexual assault). Imaging studies indicate that overactivity of the amygdala causes down-regulation of prefrontal cortical regions, especially the medial and orbital PFC.

Recent functional imaging studies indicate that effective treatment of PTSD leads to a decrease in amygdala hyper-responsiveness and an increase in prefrontal cortical activity. Understanding these functional changes may help with the discovery of new treatment options and lead to the development of therapies aimed at prevention of PTSD after severe trauma.

\section{AUTHOR AFFILIATIONS}

1. Veterans Affairs Medical Center, Huntington, West Virginia

\section{REFERENCES}

1. American Psychiatric Association. (1952). Diagnostic and statistical manual of mental disorders (1st ed.; DSM-I)

2. American Psychiatric Association. (1980). Diagnostic and statistical manual of mental disorders (3rd ed.; DSM-III)

3. American Psychiatric Association. (2013). Diagnostic and statistical manual of mental disorders (5th ed.; DSM-5). American Psychiatric Publishing

4. Janak PH, Tye KM. From circuits to behaviour in the amygdala. Nature. 2015;517(7534):284-92.

5. Arruda-Carvalho M, Clem RL. Prefrontal-amygdala fear networks come into focus. Front Syst Neurosci. 2015;9:145.

6. Likhtik E, Paz R. Amygdala-prefrontal interactions in (mal)adaptive learning. Trends Neurosci. 2015;38(3):158-66.
7. Volman I, Toni I, Verhagen L, Roelofs K. Endogenous testosterone modulates prefrontalamygdala connectivity during social emotional behavior. Cereb Cortex. 2011;21(10):2282-90.

8. Siddiqui SV, Chatterjee U, Kumar D, Siddiqui A, Goyal N. Neuropsychology of prefrontal cortex. Indian J Psychiatry. 2008;50(3):202-8.

9. Maroun M. Medial prefrontal cortex: multiple roles in fear and extinction. Neuroscientist. 2013;19(4):370-83.

10. Vouimba RM, Maroun M. Learning-induced changes in MPFC-BLA connections after fear conditioning, extinction, and reinstatement of fear. Neuropsychopharmacology. 2011;36(11):2276-85.

11. Marek R, Strobel C, Bredy TW, Sah P. The amygdala and medial prefrontal cortex: partners in the fear circuit. J Physiol. 2013;591(10):238191.

12. Francati $V$, Vermetten $E$, Bremner JD. Functional neuroimaging studies in posttraumatic stress disorder: review of current methods and findings. Depress Anxiety. 2007;24(3):202-18.

13. Hughes KC, Shin LM. Functional neuroimaging studies of post-traumatic stress disorder. Expert Rev Neurother. 2011;11(2):275-85.

14. Koenigs M, Grafman J. Posttraumatic stress disorder: the role of medial prefrontal cortex and amygdala. Neuroscientist. 2009;15(5):540-8.

15. Wolf RC, Herringa RJ. PrefrontalAmygdala Dysregulation to Threat in Pediatric Posttraumatic Stress Disorder. Neuropsychopharmacology. 2016;41(3):822-31.

16. Nutt DJ, Malizia AL. Structural and functional brain changes in posttraumatic stress disorder. J Clin Psychiatry. 2004;65 Suppl 1:11-7.

17. Rajmohan V, Mohandas E. The limbic system. Indian J Psychiatry. 2007;49(2):132-9.

18. Bhattacharyya KB. James Wenceslaus Papez, His Circuit, and Emotion. Ann Indian Acad Neurol. 2017;20(3):207-210.

19. Bizley JK, Cohen YE. The what, where and how of auditory-object perception. Nat Rev Neurosci. 2013;14(10):693-707.

20. Kravitz DJ, Saleem KS, Baker Cl, Mishkin M. A new neural framework for visuospatial processing. Nat Rev Neurosci. 2011;12(4):217-30.

21. Squire LR, Bayley PJ. The neuroscience of remote memory. Curr Opin Neurobiol. 2007;17(2):18596. 
22. McGaugh JL, Cahill L, Roozendaal B. Involvement of the amygdala in memory storage: interaction with other brain systems. Proc Natl Acad Sci U S A. 1996;93(24):13508-14.

23. Sah P, Faber ES, Lopez De Armentia M, Power J. The amygdaloid complex: anatomy and physiology. Physiol Rev. 2003;83(3):803-34.

24. Tramoni E, Felician O, Barbeau EJ, Guedj E, Guye M, Bartolomei F, Ceccaldi M. Long-term consolidation of declarative memory: insight from temporal lobe epilepsy. Brain. 2011;134(Pt 3):816-31.

25. Gardner AJ, Griffiths J. Propranolol, posttraumatic stress disorder, and intensive care: incorporating new advances in psychiatry into the ICU. Crit Care. 2014;18(6):698.

26. Wartman BC, Holahan MR. The impact of multiple memory formation on dendritic complexity in the hippocampus and anterior cingulate cortex assessed at recent and remote time points. Front Behav Neurosci. 2014;8:128.

27. Restivo L, Vetere G, Bontempi B, Ammassari-Teule $M$. The formation of recent and remote memory is associated with time-dependent formation of dendritic spines in the hippocampus and anterior cingulate cortex. J Neurosci. 2009;29(25):8206-14.

28. Lin WJ, Horner AJ, Burgess N. Ventromedial prefrontal cortex, adding value to autobiographical memories. Sci Rep. 2016;6:28630.

29. Macrae CN, Moran JM, Heatherton TF, Banfield JF, Kelley WM. Medial prefrontal activity predicts memory for self. Cereb Cortex. 2004;14(6):647-54.

30. Summerfield JJ, Hassabis D, Maguire EA. Cortical midline involvement in autobiographical memory. Neuroimage. 2009;44(3):1188-200.

31. Bryant RA, Kemp AH, Felmingham $K L$, Liddell B, Olivieri G, Peduto A, Gordon E, Williams LM. Enhanced amygdala and medial prefrontal activation during nonconscious processing of fear in posttraumatic stress disorder: an fMRI study. Hum Brain Mapp. 2008;29(5):517-23.

32. Diano M, Celeghin A, Bagnis A, Tamietto $M$. Amygdala Response to Emotional Stimuli without Awareness: Facts and Interpretations. Front Psychol. 2017;7:2029.

33. Whalley MG, Kroes MC, Huntley Z, Rugg MD, Davis SW, Brewin CR. An fMRI investigation of posttraumatic flashbacks. Brain Cogn. 2013;81(1):151-9.
34. Powers MB, Halpern JM, Ferenschak MP, Gillihan $\mathrm{SJ}$, Foa EB. A meta-analytic review of prolonged exposure for posttraumatic stress disorder. Clin Psychol Rev. 2010;30(6):635-41.

35. King AP, Block SR, Sripada RK, Rauch SA, Porter KE, Favorite TK, Giardino N, Liberzon I. A Pilot Study of Mindfulness-Based Exposure Therapy in OEF/OIF Combat Veterans with PTSD: Altered Medial Frontal Cortex and Amygdala Responses in Social-Emotional Processing. Front Psychiatry. 2016;7:154.

36. Neylan TC. Frontal Lobe Moderators and Mediators of Response to Exposure Therapy in PTSD. Am J Psychiatry. 2017; 174(12):1131-1133.

37. Mutz J, Javadi A. Exploring the neural correlates of dream phenomenology and altered states of consciousness during sleep. Neuroscience of Consciousness. 2017;2017(1).

38. Germain A. Sleep disturbances as the hallmark of PTSD: where are we now? Am J Psychiatry. 2013;170(4):372-82.

39. van Liempt S. Sleep disturbances and PTSD: a perpetual circle? Eur J Psychotraumatol. 2012;3.

40. Davis JL, Rhudy JL, Pruiksma KE, Byrd P, Williams AE, McCabe KM, Bartley EJ. Physiological predictors of response to exposure, relaxation, and rescripting therapy for chronic nightmares in a randomized clinical trial. J Clin Sleep Med. 2011;7(6):622-31.

41. Long ME, Hammons ME, Davis JL, Frueh BC, Khan MM, Elhai JD, Teng EJ. Imagery rescripting and exposure group treatment of posttraumatic nightmares in Veterans with PTSD. J Anxiety Disord. 2011;25(4):531-5.

42. Ulrich-Lai YM, Herman JP. Neural regulation of endocrine and autonomic stress responses. Nat Rev Neurosci. 2009;10(6):397-409.

43. Yehuda R, LeDoux J. Response variation following trauma: a translational neuroscience approach to understanding PTSD. Neuron. 2007;56(1):19-32.

44. Pineles SL, Suvak MK, Liverant Gl, Gregor K, Wisco BE, Pitman RK, Orr SP. Psychophysiologic reactivity, subjective distress, and their associations with PTSD diagnosis. J Abnorm Psychol. 2013;122(3):635-44.

45. Ongür $D, A n X$, Price JL. Prefrontal cortical projections to the hypothalamus in macaque monkeys. J Comp Neurol. 1998;401 (4):480-505.

46. Ongür $\mathrm{D}$, Price JL. The organization of networks within the orbital and medial prefrontal cortex 
of rats, monkeys and humans. Cereb Cortex. 2000;10(3):206-19.

47. Spencer SJ, Buller KM, Day TA. Medial prefrontal cortex control of the paraventricular hypothalamic nucleus response to psychological stress: possible role of the bed nucleus of the stria terminalis. J Comp Neurol. 2005;481(4):36376.

48. Reppucci CJ, Petrovich GD. Organization of connections between the amygdala, medial prefrontal cortex, and lateral hypothalamus: a single and double retrograde tracing study in rats. Brain Struct Funct. 2016;221(6):2937-62.

49. Williams LM, Liddell BJ, Kemp AH, Bryant RA, Meares RA, Peduto AS, Gordon E. Amygdalaprefrontal dissociation of subliminal and supraliminal fear. Hum Brain Mapp. 2006;27(8):652-61.

50. Naegeli $C$, Zeffiro T, Piccirelli $M$, Jaillard $A$, Weilenmann A, Hassanpour K, Schick M, Rufer M, Orr SP, Mueller-Pfeiffer C. Locus Coeruleus Activity Mediates Hyperresponsiveness in Posttraumatic Stress Disorder. Biol Psychiatry. 2018;83(3):254-262.

51. Berridge CW, Schmeichel BE, España RA. Noradrenergic modulation of wakefulness/ arousal. Sleep Med Rev. 2012;16(2):187-97.

52. Uematsu A, Tan BZ, Johansen JP. Projection specificity in heterogeneous locus coeruleus cell populations: implications for learning and memory. Learn Mem. 2015;22(9):444-51.

53. Jodo E, Chiang C, Aston-Jones G. Potent excitatory influence of prefrontal cortex activity on noradrenergic locus coeruleus neurons. Neuroscience. 1998;83(1):63-79.

54. Pietrzak RH, Gallezot JD, Ding YS, Henry S, Potenza MN, Southwick SM, Krystal JH, Carson RE, Neumeister A. Association of posttraumatic stress disorder with reduced in vivo norepinephrine transporter availability in the locus coeruleus. JAMA Psychiatry. 2013;70(11):1199-205.

55. Naegeli $C$, Zeffiro T, Piccirelli $M$, Jaillard $A$, Weilenmann A, Hassanpour K, Schick M, Rufer M, Orr SP, Mueller-Pfeiffer C. Locus Coeruleus Activity Mediates Hyperresponsiveness in Posttraumatic Stress Disorder. Biol Psychiatry. 2018;83(3):254-262.

56. Boehnlein JK, Kinzie JD. Pharmacologic reduction of CNS noradrenergic activity in PTSD: the case for clonidine and prazosin. J Psychiatr Pract. 2007;13(2):72-8.

57. Hilton L, Maher AR, Colaiaco B, Apaydin E, Sorbero ME, Booth M, Shanman RM, Hempel S. Meditation for posttraumatic stress: Systematic review and meta-analysis. Psychol Trauma. 2017;9(4):453-460.

58. Leung MK, Lau WKW, Chan CCH, Wong SSY, Fung ALC, Lee TMC. Meditation-induced neuroplastic changes in amygdala activity during negative affective processing. Soc Neurosci. 2017;Apr 10:112.

59. Doll A, Hölzel BK, Mulej Bratec S, Boucard CC, Xie $X$, Wohlschläger AM, Sorg C. Mindful attention to breath regulates emotions via increased amygdala-prefrontal cortex connectivity. Neuroimage. 2016;134:305-313.

60. De Oca BM, DeCola JP, Maren S, Fanselow MS. Distinct regions of the periaqueductal gray are involved in the acquisition and expression of defensive responses. J Neurosci. 1998;18(9):342632.

61. Rabellino D, Densmore M, Frewen PA, Théberge $\mathrm{J}$, Lanius RA. The innate alarm circuit in posttraumatic stress disorder: Conscious and subconscious processing of fear- and traumarelated cues. Psychiatry Res. 2016;248:142-50.

62. Lee Y, López DE, Meloni EG, Davis M. A primary acoustic startle pathway: obligatory role of cochlear root neurons and the nucleus reticularis pontis caudalis. J Neurosci. 1996;16(11):3775-89.

63. Shalev AY, Peri T, Brandes D, Freedman S, Orr SP, Pitman RK. Auditory startle response in trauma survivors with posttraumatic stress disorder: a prospective study. Am J Psychiatry. 2000;157(2):255-61.

64. Tovote P, Esposito MS, Botta P, Chaudun F, Fadok JP, Markovic M, Wolff SB, Ramakrishnan C, Fenno L, Deisseroth K, Herry C, Arber S, Lüthi A. Midbrain circuits for defensive behaviour. Nature. 2016;534(7606):206-12.

65. Davis M, Walker DL, Lee Y. Roles of the amygdala and bed nucleus of the stria terminalis in fear and anxiety measured with the acoustic startle reflex. Possible relevance to PTSD. Ann NY Acad Sci. 1997;821:305-31.

66. Barrett DW, Gonzalez-Lima F. Prefrontal-limbic Functional Connectivity during Acquisition and Extinction of Conditioned Fear. Neuroscience. 2018;376:162-171. 
67. Basar K, Sesia T, Groenewegen H, Steinbusch HW, Visser-Vandewalle V, Temel Y. Nucleus accumbens and impulsivity. Prog Neurobiol. 2010;92(4):53357.

68. Shiflett MW, Balleine BW. At the limbic-motor interface: disconnection of basolateral amygdala from nucleus accumbens core and shell reveals dissociable components of incentive motivation. Eur J Neurosci. 2010;32(10):1735-43.

69. Finch DM. Neurophysiology of converging synaptic inputs from the rat prefrontal cortex, amygdala, midline thalamus, and hippocampal formation onto single neurons of the caudate/ putamen and nucleus accumbens. Hippocampus. 1996;6(5):495-512.

70. Burns LH, Annett L, Kelley AE, Everitt BJ, Robbins TW. Effects of lesions to amygdala, ventral subiculum, medial prefrontal cortex, and nucleus accumbens on the reaction to novelty: implication for limbic-striatal interactions. Behav Neurosci. 1996;110(1):60-73.

71. Zald DH. The human amygdala and the emotional evaluation of sensory stimuli. Brain Res Brain Res Rev. 2003;41(1):88-123.

72. Meyer HC, Bucci DJ. Imbalanced Activity in the Orbitofrontal Cortex and Nucleus Accumbens Impairs Behavioral Inhibition. Curr Biol. 2016;26(20):2834-2839.

73. Dolan RJ. The human amygdala and orbital prefrontal cortex in behavioural regulation. Philos Trans R Soc Lond B Biol Sci. 2007;362(1481):78799.

74. Blair RJ. The roles of orbital frontal cortex in the modulation of antisocial behavior. Brain Cogn. 2004;55(1):198-208.

75. Davidson RJ, Putnam KM, Larson CL. Dysfunction in the neural circuitry of emotion regulation-a possible prelude to violence. Science. 2000;289(5479):591-4.

76. Hakamata $Y$, Matsuoka $Y$, Inagaki M, Nagamine M, Hara E, Imoto S, Murakami K, Kim Y, Uchitomi Y. Structure of orbitofrontal cortex and its longitudinal course in cancer-related post-traumatic stress disorder. Neurosci Res. 2007;59(4):383-9.

77. Sadeh N, Spielberg JM, Hayes JP. Impulsive responding in threat and reward contexts as a function of PTSD symptoms and trait disinhibition. J Anxiety Disord. 2018;53:76-84.

78. Thomaes K, Dorrepaal E, Draijer N, de Ruiter MB, van Balkom AJ, Smit JH, Veltman DJ. Reduced anterior cingulate and orbitofrontal volumes in child abuse-related complex PTSD. J Clin Psychiatry. 2010;71(12):1636-44.

79. Jackowski AP, Araújo Filho GM, Almeida AG, Araújo CM, Reis $M$, Nery F, Batista IR, Silva I, Lacerda AL. The involvement of the orbitofrontal cortex in psychiatric disorders: an update of neuroimaging findings. Rev Bras Psiquiatr. 2012;34(2):207-12.

80. Gu X, Hof PR, Friston KJ, Fan J. Anterior insular cortex and emotional awareness. J Comp Neurol. 2013;521(15):3371-88.

81. Mesulam MM, Mufson EJ. Insula of the old world monkey. III: Efferent cortical output and comments on function. J Comp Neurol. 1982;212(1):38-52.

82. Critchley HD, Harrison NA. Visceral influences on brain and behavior. Neuron. 2013;77(4):624-38.

83. Shura RD, Hurley RA, Taber KH. Insular cortex: structural and functional neuroanatomy. J Neuropsychiatry Clin Neurosci. 2014;26(4):27682.

84. Shiba Y, Oikonomidis L, Sawiak S, Fryer TD, Hong YT, Cockcroft G, Santangelo AM, Roberts AC. Converging Prefronto-Insula-Amygdala Pathways in Negative Emotion Regulation in Marmoset Monkeys. Biol Psychiatry. 2017;82(12):895-903.

85. Stein MB, Simmons AN, Feinstein JS, Paulus MP. Increased amygdala and insula activation during emotion processing in anxiety-prone subjects. Am J Psychiatry. 2007;164(2):318-27.

86. Bruce SE, Buchholz KR, Brown WJ, Yan L, Durbin $A$, Sheline YI. Altered emotional interference processing in the amygdala and insula in women with Post-Traumatic Stress Disorder. Neuroimage Clin. 2012;2:43-9.

87. Amodio DM, Frith CD. Meeting of minds: the medial frontal cortex and social cognition. Nat Rev Neurosci. 2006;7(4):268-77.

88. Meyer ML, Lieberman MD. Why People Are Always Thinking about Themselves: Medial Prefrontal Cortex Activity during Rest Primes Self-referential Processing. J Cogn Neurosci. 2018;30(5):714-721.

89. Salzman CD, Fusi S. Emotion, cognition, and mental state representation in amygdala and prefrontal cortex. Annu Rev Neurosci. 2010;33:173-202.

90. Quirk GJ, Beer JS. Prefrontal involvement in 
the regulation of emotion: convergence of rat and human studies. Curr Opin Neurobiol. 2006;16(6):723-7.

91. McLean CP, Foa EB. Emotions and emotion regulation in posttraumatic stress disorder. Curr Opin Psychol. 2017;14:72-77.

92. Boden MT, Westermann S, McRae K, Kuo J, Alvarez J, Kulkarni MR, Gross JJ, Bonn-Miller MO. Emotion Regulation and Posttraumatic Stress Disorder: A Prospective Investigation. Journal of Social and Clinical Psychology. 2013;32(3):296-314.

93. Fonzo GA, Goodkind MS, Oathes DJ, Zaiko YV, Harvey M, Peng KK, Weiss ME, Thompson AL, Zack SE, Mills-Finnerty CE, Rosenberg BM, Edelstein $\mathrm{R}$, Wright RN, Kole CA, Lindley SE, Arnow BA, Jo B, Gross JJ, Rothbaum BO, Etkin A. Selective Effects of Psychotherapy on Frontopolar Cortical Function in PTSD. Am J

94. Psychiatry. 2017;174(12):1175-1184.

95. MacNamara, A., Rabinak, C. A., Kennedy, A. E., Fitzgerald, D. A., Liberzon, I., Stein, M. B., \& Phan, K. L. Emotion Regulatory Brain Function and SSRI Treatment in PTSD: Neural Correlates and Predictors of Change. Neuropsychopharmacology. 2016;41(2):611-618.

96. Terasawa Y, Shibata M, Moriguchi Y, Umeda S. Anterior insular cortex mediates bodily sensibility and social anxiety. Soc Cogn Affect Neurosci. 2013;8(3):259-66.

97. Brunet A, Thomas É, Saumier D, Ashbaugh AR, Azzoug A, Pitman RK, Orr SP, Tremblay J. Trauma reactivation plus propranolol is associated with durably low physiological responding during subsequent script-driven traumatic imagery. Can J Psychiatry. 2014;59(4):228-32.

98. Shin LM, Rauch SL, Pitman RK. Amygdala, medial prefrontal cortex, and hippocampal function in PTSD. Ann N Y Acad Sci. 2006;1071:67-79.

99. Liberzon I, Sripada CS. The functional neuroanatomy of PTSD: a critical review. Prog Brain Res. 2008;167:151-69.

100. Naumann RK, Ondracek JM, Reiter S, Shein-Idelson M, Tosches MA, Yamawaki TM, Laurent. G The reptilian brain. Curr Biol. 2015;25(8):R317-R321.

101. Steimer T. The biology of fear- and anxietyrelated behaviors. Dialogues Clin Neurosci. 2002;4(3):231-249. 